\title{
QUASI-ISOTROPIC CARBON-CARBON HYBRID LAMINATE: STATIC AND LOW-CYCLIC PERFORMANCE
}

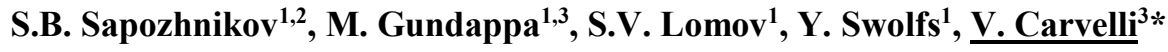 \\ ${ }^{1}$ Department of Materials Engineering, KU Leuven, Belgium \\ ${ }^{2}$ South Ural State University, Chelyabinsk, Russia \\ ${ }^{3}$ Department A.B.C., Politecnico di Milano, Italy \\ * valter.carvelli@polimi.it
}

The main strategy to make composite materials more damage tolerant and less brittle is the hybridization. The interlayer hybridization is the simplest way consisting of low-elongation and high-elongation layers. In this context, few studies have been focused on interlayer all-carbon quasi-isotropic laminates (see e.g. [1]). This is the topic of the present work dealing with the pseudo-ductile (PD) behavior of a laminate [0/45/90/-45] both for quasi-static and low-cyclic tensile. Different than [1], in this work the laminates had conventional layer thickness.

The quasi-static tensile tests of the laminate (with and without open hole) have been assisted by acoustic emission (AE) recording and strain mapping (DIC technique) to detect the initiation and development of the damage. The low-cycle tensile-tensile performance for different stress levels allowed to assess the effect of the pseudo-ductile behavior on the creep of the material. UD ultra-high modulus (D) and high-strength (T) carbon fibers prepregs (DIALEAD and T800 fibers with epoxy) were used to get stable PD effect in tension [2]. Hybrids sub-laminates, namely $\mathrm{T} / \mathrm{D} / \mathrm{T}$ and $\mathrm{T}_{2} / \mathrm{D} / \mathrm{T}_{2}$, were used to get quasi-isotropic $(\mathrm{QI})$ behavior. The $\mathrm{QI}$ laminate showed the typical ' $1 / 3$ ' rule of the classic laminate theory for the elastic stiffness as well as for the PD stress level, namely they are $1 / 3$ of T/D/T UD laminate (Figure 1).

QI specimens with open holes showed complete insensitivity to the stress concentrations under tension. Tension-tension repeated loading of QI PD hybrid laminate showed measurable creep, decreasing of the stiffness and the stable growth of acoustic events. In this work, low-cyclic loading consisted of only 50 -cycles at the frequency of $0.01 \mathrm{~Hz}$. It allowed, by acoustic emissions and DIC, as for quasi-static tests, to investigate low-cyclic mechanical properties degradation. The latter are the background to set, in the future, a comprehensive study on the fatigue of the hybrid CFRP with the knowledge of static and creep behaviors.
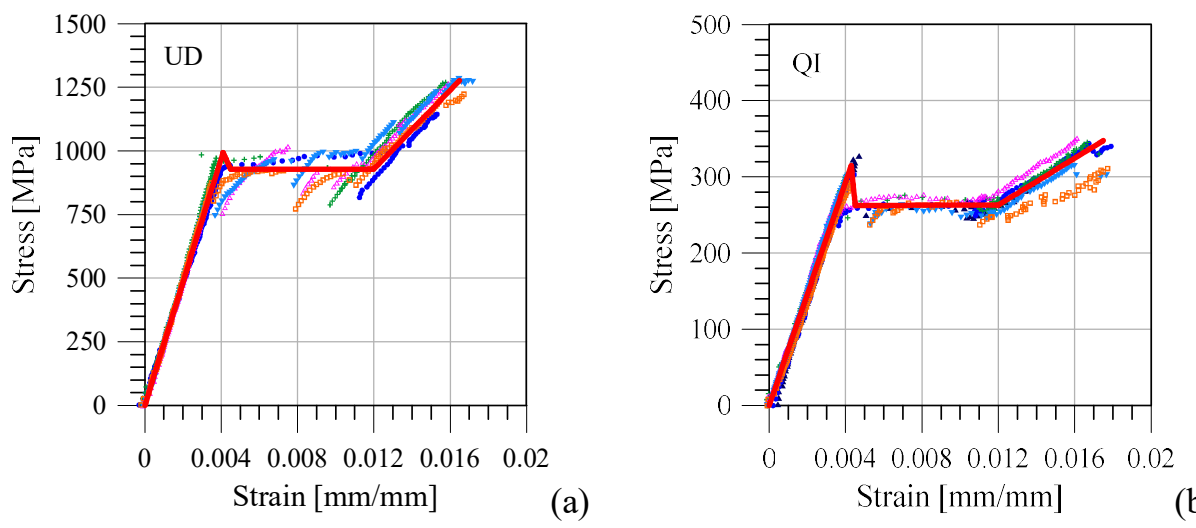

Figure 1. Stress-strain curves for (a) [T/D/T] UD and (b) [T/D/T] QI laminates.

\section{References}

[1] G. Czél et al. (2018), 'Pseudo-ductility and reduced notch sensitivity in multi-directional all-carbon/epoxy thin-ply hybrid composites', Composites A, 104, 151-164.

[2] S. B. Sapozhnikov, Y. Swolfs, and S. V. Lomov (2020), Pseudo-ductile unidirectional high modulus/high strength carbon fibre hybrids using conventional ply thickness prepregs, Composites B, 198, 108213 